\title{
Effect of Standardized Infliximab Dose Rounding on an Outpatient Infusion Center
}

\author{
Jiyeon Joy Park, PharmD; Lauren Boutillier, PharmD, BCOP; Joseph E. Cruz, PharmD, BCPS; \\ GaEun Joung, PharmD, BCPS; and Jeffrey Nemeth, PharmD, MPA
}

\begin{abstract}
BACKGROUND: Infliximab dose rounding is a commonly accepted practice at many institutions to contain costs. Currently, there is limited data on the clinical and financial implications of infliximab dose rounding standardization.

OBJECTIVE: To determine whether standardized infliximab dose rounding is comparable with nonstandardized dosing in patients with Crohn's disease or ulcerative colitis in terms of cost and efficiency, using a cost comparison between the 2 dosing methods at an outpatient infusion center attached to a community teaching hospital.
\end{abstract}

METHODS: A retrospective electronic chart review was conducted to identify patients who received infliximab for ulcerative colitis or Crohn's disease over a 6-month period. The primary endpoint was cost comparison between the 2 dosing methods. The secondary outcomes were estimated time taken for order verification, number of order clarifications, increase in dose or frequency of infliximab, number of patients who switched to alternative therapy, and use of medications for adverse drug effects. Descriptive statistics and Fisher's exact test were used for data analysis.

RESULTS: 72 patients met the inclusion criteria. Because of patient overlap during the study period, 45 patients $(62.5 \%)$ were in the standardized rounding arm, and 69 patients (95.8\%) were in the nonstandardized rounding arm. One patient in each arm required an increased dose or frequency of infusion $(2.2 \%$ vs. $1.5 \%, P=1.000)$. Standardized infliximab dose rounding had a theoretical cost savings of at least $\$ 104,640$ per year (based on our rough annual census of 480 patients) compared with the nonstandardized method that had been used previously. The cost savings can also be translated as $\$ 218$ per patient per month on average. The mean times to order verification were 10 vs. 12 minutes in the nonstandardized and standardized groups, respectively. Two patients in the nonstandardized group switched to alternative therapy. There was no difference in usage of rescue medications for adverse drug effects.

CONCLUSIONS: Standardization of infliximab dose rounding resulted in increased efficiency in the pharmacy workflow by reducing time for order verification. Furthermore, standardized dose rounding resulted in a significant reduction in expenditure for infliximab for the institution.

J Manag Care Spec Pharm. 2018;24(10):1028-33

Copyright $\odot 2018$, Academy of Managed Care Pharmacy. All rights reserved.

\section{What is already known about this subject}

Infliximab is a costly biologic and accounts for a large percentage of expenditure in many different institutions and clinics.

There is no standard approach to dose rounding for infliximab, and limited data are available concerning the financial and clinical effect of using standardized dose rounding.

\section{What this study adds}

This study demonstrated that standardization of infliximab dose rounding may result in significant cost savings to an outpatient infusion center.

Using standardized dosing may facilitate pharmacy workflow by saving time from order entry to verification.

I nfliximab is responsible for the top drug expenditure in hospitals and clinics across the United States. ${ }^{1}$ The pharmacy department at Englewood Hospital and Medical Center (EHMC) spent $\$ 2.7$ million on infliximab from May 2016 to April 2017. As of September 2017, the cost for the EHMC pharmacy to obtain one $100 \mathrm{mg}$ vial of infliximab was $\$ 1,111.22$; according to RED BOOK Online, the wholesale acquisition cost as of February 2017 was $\$ 1,167.82 .^{2}$ At the EHMC outpatient infusion center, the approximate number of infliximab patient visits per month ranges from 40 to 50 .

Infliximab is a monoclonal antibody that inhibits tumor necrosis factor-alpha and is used to treat Crohn's disease, ulcerative colitis, rheumatoid arthritis, and other autoimmune diseases. Some of the common adverse effects include rash, nausea, and hypersensitivity reactions. Premedication with acetaminophen and diphenhydramine is necessary to prevent infusion-related reactions. Dosing is weight-based for all indications; more specifically, for Crohn's disease and ulcerative colitis, the typical dose is $5 \mathrm{mg}$ per $\mathrm{kg}(\mathrm{mg} / \mathrm{kg})$ intravenously at weeks 0,2 , and 6 for the induction therapy followed by $5 \mathrm{mg} / \mathrm{kg}$ intravenously every 8 weeks. The typical maximum dose is $10 \mathrm{mg} / \mathrm{kg}$ intravenously every 8 weeks. ${ }^{3}$

Because of the high cost of biologics, including infliximab, dose rounding has become a common practice at many institutions in order to avoid wasting partially used vials. Although some institutions follow practices such as a "10\% rule," in which the calculated dose is rounded to the nearest vial if the rounded dose falls within 10\% change from the calculated dose, many other institutions nationwide (38\%) do not have a standardized approach to infliximab dose rounding. ${ }^{4-6}$ Historically at EHMC, a general rule for dose rounding has been $\pm 10 \%$ of the original dose. However, since infliximab relies on weight-based dosing, dose modification was often 


\begin{tabular}{|c|c|c|c|c|c|c|}
\hline $\begin{array}{l}\text { Weight } \\
(\mathrm{kg})\end{array}$ & $\begin{array}{c}\begin{array}{c}\text { Dose } \\
(\mathrm{mg})\end{array} \\
3 \mathrm{mg} / \mathrm{kg}\end{array}$ & $\begin{array}{c}\begin{array}{c}\text { Dose } \\
(\mathrm{mg})\end{array} \\
5 \mathrm{mg} / \mathrm{kg}\end{array}$ & $\begin{array}{c}\text { Weight } \\
(\mathrm{kg})\end{array}$ & $\begin{array}{c}\begin{array}{c}\text { Dose } \\
(\mathrm{mg})\end{array} \\
10 \mathrm{mg} / \mathrm{kg}\end{array}$ & $\begin{array}{l}\text { Weight } \\
\text { (kg) }\end{array}$ & $\begin{array}{c}\text { Dose } \\
(\mathrm{mg}) 10 \\
\mathrm{mg} / \mathrm{kg} \\
\end{array}$ \\
\hline $30-39$ & 100 & 175 & $30-34$ & 325 & $105-109$ & 1,050 \\
\hline $40-49$ & 125 & 200 & $35-39$ & 350 & $110-114$ & 1,100 \\
\hline $50-59$ & 150 & 250 & $40-44$ & 400 & $115-119$ & 1,150 \\
\hline $60-69$ & 200 & 300 & $45-49$ & 450 & $120-124$ & 1,200 \\
\hline 70-79 & 200 & 350 & $50-54$ & 500 & $125-129$ & 1,250 \\
\hline $80-89$ & 250 & 400 & $55-59$ & 550 & $130-134$ & 1,300 \\
\hline $90-99$ & 250 & 450 & $60-64$ & 600 & $135-139$ & 1,350 \\
\hline 100-109 & 300 & 500 & $65-69$ & 650 & $140-144$ & 1,400 \\
\hline $110-119$ & 300 & 550 & $70-74$ & 700 & $145-149$ & 1,450 \\
\hline $120-129$ & 350 & 600 & $75-79$ & 750 & $150-154$ & 1,500 \\
\hline $130-139$ & 400 & 650 & $80-84$ & 800 & $155-159$ & 1,550 \\
\hline $140-149$ & 400 & 700 & $85-89$ & 850 & $160-164$ & 1,600 \\
\hline 150-159 & 450 & 750 & $90-94$ & 900 & $165-169$ & 1,650 \\
\hline 160-169 & 450 & 800 & 95-99 & 950 & $170-174$ & 1,700 \\
\hline 170-179 & 500 & 850 & $100-104$ & 1,000 & $175-179$ & 1,750 \\
\hline
\end{tabular}

necessary to reflect the most current patient weight. Even with the $10 \%$ rule in mind, it was noted that prescribing and dose rounding patterns widely varied across prescribers, and there was no standardized approach to dose rounding. This lack of standardization resulted in frequent calls by the pharmacists to prescribers to clarify doses and weights. Subsequently, treatments were often delayed because of the lack of efficiency in this process.

In order to solve this issue, a standardized dose rounding chart (Table 1) was added to infliximab order sets and introduced to EHMC outpatient infusion center staff in January 2017. The standardized chart rounds doses down but still keeps them within the $10 \%$ range. This change was made to facilitate pharmacy workflow, reduce drug waste and vials procured, and minimize the number of prescriber calls to clarify orders. When using the dose rounding chart, prescribers had the option to either select the dose based on the rounding chart or prescribe a flat dose based on their own practices of dose rounding.

Currently, there is no data on the implication of any type of biologic dose rounding, including infliximab. There is a need to examine the clinical and financial effects of this particular method of dose rounding (Table 1). The objective of this study was to assess cost and efficiency of infliximab standardized dose rounding in patients with Crohn's disease or ulcerative colitis.

\section{Methods}

A retrospective chart review from October 1, 2016, to March 31, 2017, was conducted using McKesson Horizon Meds Manager (an electronic pharmacy system) and Horizon Patient Folder (an electronic archive of scanned copies of patient charts). The

\section{TABLE 2 Baseline Characteristics}

\begin{tabular}{l|c|c}
\hline & $\begin{array}{c}\text { Nonstandardized } \\
(\mathbf{n}=69)\end{array}$ & $\begin{array}{c}\text { Standardized } \\
(\mathbf{n}=45)\end{array}$ \\
\hline Age, mean (years) & 42 & 41 \\
\hline Female, \% (n) & $55.1(38)$ & $55.6(25)$ \\
\hline Diagnosis, \% (n) & $58.0(40)$ & $64.4(29)$ \\
\hline Crohn's disease & $42.0(29)$ & $35.6(16)$ \\
\hline Ulcerative colitis & 27 & 27 \\
\hline Body mass index, mean $\left(\mathrm{kg} / \mathrm{m}^{2}\right)$ & 75.8 & 76.9 \\
\hline Weight, mean $(\mathrm{kg})$ & 76.3 & 73.9 \\
\hline Weight, median $(\mathrm{kg})$ & $43.0-126.8$ & $45.8-126.1$ \\
\hline Weight range $(\mathrm{kg})$ & 25.1 & 24.5 \\
\hline Weight, interquartile range $(\mathrm{kg})$ & 5 & 5 \\
\hline Dose, median $(\mathrm{mg} / \mathrm{kg})$ & 5 & 5 \\
\hline Dose, interquartile range $(\mathrm{mg} / \mathrm{kg})$ & 8 & 8 \\
\hline Frequency, median $(w e e k s)$ & 154 & 63 \\
\hline Total number of doses & &
\end{tabular}

study included patients who received infliximab for Crohn's disease or ulcerative colitis at the EHMC outpatient infusion center over this 6-month period, including 3 months before implementation of standardized dose rounding and 3 months after implementation. Patients were excluded from the study if they weighed less than $30 \mathrm{~kg}$ or more than $179 \mathrm{~kg}$, received infliximab during an inpatient stay at any given period, and if they were treated for indications other than Crohn's disease or ulcerative colitis.

The primary outcome was cost comparison between nonstandardized dose rounding, standardized dose rounding, and theoretical exact dosing. Exact dosing is defined here as the product of the weight-based dose and the patient's actual weight on the day of treatment. There were no patients who weighed less than $30 \mathrm{~kg}$ or more than $179 \mathrm{~kg}$. Secondary outcomes included time from patient's weight measurement to order verification by pharmacists, number of order clarifications, the need to switch to an alternative therapy for Crohn's disease or ulcerative colitis, and increase in dose or frequency. Any use of rescue medications for adverse drug effects (ADE) was recorded to assess safety of infliximab standardized dose rounding versus nonstandardized dose rounding.

With the differences in the number of patients in each arm, a direct cost comparison of infliximab use in both arms was not practical. In order to mitigate this conundrum, we devised a theoretical value called the "efficiency factor" to normalize the number of total vials used relative to the prescribed dose in milligrams. The efficiency factor represented the number of vials used per each prescribed dose of $100 \mathrm{mg}$ over the study period. This calculation is a numerical value of the total milligrams of infliximab used or wasted across all patients divided by the total dose ordered across all patients: 


\begin{tabular}{l|c|c|c}
\hline TABLE 3 & \multicolumn{2}{l}{$\begin{array}{l}\text { Estimated Cost Savings If } \\
\text { Nonstandardized Group Was } \\
\text { Standardized }\end{array}$} \\
\hline & $\begin{array}{c}\text { Nonstandardized } \\
(\mathbf{n}=69)\end{array}$ & $\begin{array}{c}\text { Standardized } \\
\text { (Theoretical) }\end{array}$ & $\begin{array}{c}\text { Exact } \\
\text { (Theoretical) }\end{array}$ \\
\hline Total vials used, $\mathrm{n}$ & 773 & 733 & 808 \\
\hline Cost, \$ & 859,421 & 814,949 & 898,334 \\
\hline $\begin{array}{l}\text { Difference from } \\
\text { Nonstandardized, \$ }\end{array}$ & & $-44,472$ & $+38,913$ \\
\hline
\end{tabular}

Note: The 69 patients in the nonstandardized group used 773 vials over approximately 3 months. Compared with theoretical exact dosing (which would have no rounding at all), there is some cost reduction, indicating some extent of dose rounding even in the nonstandardized group. However, if the nonstandardized group followed standardized dose rounding, it would have saved 40 vials or $\$ 44,472-$ $\$ 44,472$ dollars per 3 months per 69 patients can be translated to $\$ 218$ per patient per month or $\$ 2,616$ per patient per year.

Efficiency factor: (Actual \# vials $\times \mathrm{mg} \div$ sum of actual doses [mg]) Nonstandardized $(\mathrm{n}=69): 773$ vials $\times 100 \mathrm{mg} \div 72,217 \mathrm{mg}=1.07$ Standardized $(\mathrm{n}=45): 306$ vials $\times 100 \mathrm{mg} \div 29,100 \mathrm{mg}=1.05$

Taking this calculation a step further, we devised a "number needed to waste," which represented the number of vials used, when preparing infliximab doses, until a vial would be theoretically wasted. In the nonstandardized group, approximately 1 vial was wasted for every 14 vials used. In the standardized group, approximately 1 vial was wasted for every 19 vials used, signifying less waste generation by using standardized dose rounding. The calculation for the number needed to waste is as follows:

Number needed to waste: $(1 \div[$ Efficiency Factor -1$])$

Nonstandardized: $1 \div(1.07-1)=14.2$

Standardized: $1 \div(1.05-1)=19.4$

The Fischer's exact test was used to analyze categorical data. Descriptive statistics were used to compare other measured variables between the 2 groups. This study was approved by the EHMC institutional review board.

\section{Results}

Seventy-two patients met the inclusion criteria. Once the practice of standardization was implemented, patients who were previously receiving nonstandardized rounded doses were transitioned to care with standardized rounding. As such, there were some patients who overlapped between the 2 evaluated groups. In total, 69 patients were evaluated who received nonstandardized dose rounding in the period from October 1 , 2016, to March 25, 2017, and 45 patients were evaluated after being treated with standardized dose rounding (Appendix). The baseline characteristics of both arms were similar (Table 2).

The nonstandardized group $(\mathrm{n}=69)$ used 773 vials over approximately 3 months. If the nonstandardized group would

\begin{tabular}{c|c|c}
\hline TABLE 4 & $\begin{array}{c}\text { Theoretical Cost Savings Based on } \\
\text { Number of Patients Receiving Infliximab }\end{array}$ \\
\hline $\begin{array}{c}\text { Patients } \\
\text { per Month, } \mathbf{n}\end{array}$ & $\begin{array}{c}\text { Cost Saved } \\
\text { per Month, } \mathbf{\$}\end{array}$ & $\begin{array}{c}\text { Cost Saved } \\
\text { per Year, } \mathbf{\$}\end{array}$ \\
\hline 30 & 6,540 & 78,480 \\
\hline 40 & 8,720 & 104,640 \\
\hline 50 & 10,900 & 130,800 \\
\hline 60 & 13,800 & 165,600 \\
\hline
\end{tabular}

have been treated using the standardized dose rounding chart, it is estimated that 40 vials of infliximab would have been saved for a cost avoidance of $\$ 44,472$ during the 3-month period (Table 3). If this savings were extrapolated out over an entire year, assuming 40 patients receive infliximab for Crohn's disease or ulcerative colitis per month, the total theoretical cost avoidance per year would be $\$ 104,640$ at EHMC (Table 4). This cost avoidance can also be converted to $\$ 218$ per patient per month or $\$ 2,616$ per patient per year.

One patient each in the nonstandardized and standardized dosing groups had an increase in dose or frequency (nonstandardized: 1 of 69 patients, 1.5\%; standardized: 1 of 45 patients, $2.2 \% ; P=1.000)$. Two patients $(2.9 \%)$ switched to alternative therapy in the nonstandardized group. No patient required alternative therapies in the standardized group. The overall rate of order clarification needed was similar between the 2 groups (6.5\% standardized vs. $6.4 \%$ nonstandardized). The mean time from weight measurement to order verification was 10 minutes in the standardized group and 12 minutes in the nonstandardized group. There was no use of rescue medications for ADEs in either group.

The extent of dose rounding in the studied patients was obtained by calculating the mean difference between their actual administered doses and the theoretical exact calculated doses. In the nonstandardized group, the average percentage of dose rounding was $-1.7 \%$ versus $-4.3 \%$ in the standardized group, indicating that, as compared with the nonstandardized rounding, the standardized rounding method resulted in doses that differed more greatly from the exact calculated dose. However, the absolute range of dose rounding was larger in the nonstandardized group $(-31.3 \%$ to $+9.3 \%)$ versus the standardized group (-10.8\% to $+0.9 \%$; Figure 1$)$.

\section{Discussion}

Overall, the use of a standardized method of infliximab dose rounding resulted in similar care at a lower cost compared with the previous practice of nonstandardized, prescriber-specific doses. The rate of need for order clarification, use of rescue treatment for ADEs, and increase in dose or frequency of infliximab were similar between the 2 groups. Previously, a singlecenter study demonstrated that pharmacist-guided automatic 


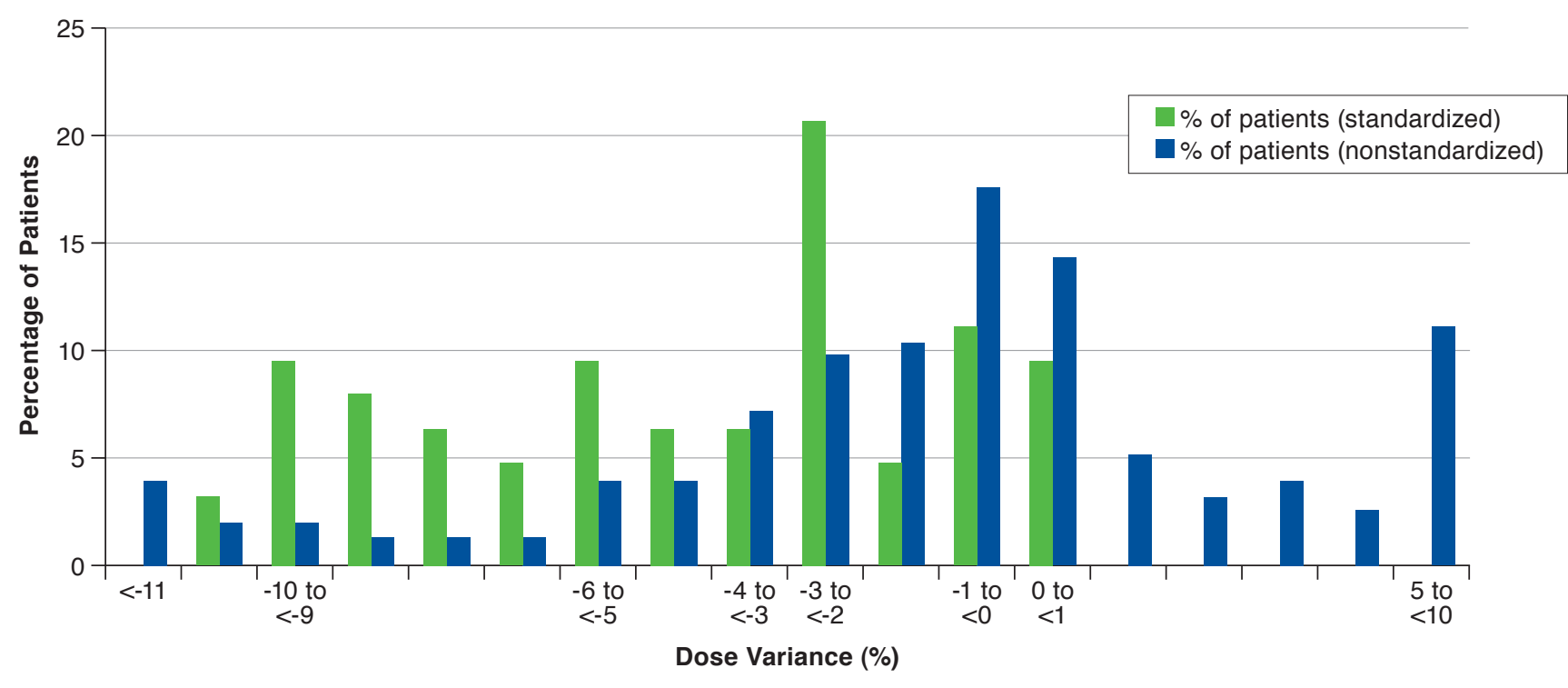

dose rounding resulted in a significant cost saving. ${ }^{4}$ In that study, automatic dose rounding of 6,216 doses of biologics (following the $\pm 10 \%$ rule) and antineoplastics ( $\pm 5 \%$ rule) resulted in a cost saving of $\$ 200,000$ in 1 year.

In addition to estimating the number of vials spared, our study also sought to quantify the time saved per each order verification. We found that the average time from weight measurement to order verification was slightly longer in the standardized group, although if the first time use of the standardized dosing form was excluded, the average time in the standardized group would have been 8 minutes (vs. 10 minutes in the nonstandardized group). This finding seems to indicate that the standardized method may be slightly more efficient overall after accounting for a modest learning curve, although the minor difference in time likely is not practically meaningful.

The standardization implementation at our institution was well received by prescribers and staff and is a common practice that continues to the present-the majority of prescribers use the standardized rounding chart even though there is still an option for prescribers to order nonstandard doses of infliximab. In the future, there is a need for a larger, longer, multicenter study to validate the applicability of our findings to other institutions and care settings, although to our knowledge, this is the first published findings of clinical and financial effects of standardizing infliximab dose rounding for patients with Crohn's disease and ulcerative colitis.

\section{Limitations}

This study has some limitations to consider. The use of surrogate markers, such as time from weight measurement to order verification, may not entirely quantify efficiency. Also, this study was a single-center retrospective chart review, so there is more potential for selection bias than a prospective randomized controlled trial. Furthermore, because of infliximab's relatively infrequent dosing (i.e., every 8 weeks), the period of 6 months may not have captured a true difference in dose or frequency adjustments made between the 2 groups. Also, the follow-up period beyond the predefined 6-month period was not assessed. In a previous retrospective chart review, which included 161 adult patients with Crohn's disease, only 18 patients (17\%) had dose escalation of infliximab over a 4-year period. ${ }^{7}$

Finally, time bias was present against the standardized group, which did not take into account disease progression over time and antibody development with prolonged use of infliximab. This was unavoidable because of the large amount of overlap between patients who first received nonstandardized dose rounding before transitioning to the standardized method. A future study with a longer follow-up period is needed, and analyzing serum infliximab levels may provide useful insights for patients who do not respond to infliximab.

\section{Conclusions}

With its ease of use, standardized infliximab dose rounding could provide improved pharmacy workflow that would save time and the need to make extra phone calls. Significant cost avoidance was realized with standardization of infliximab dose rounding. 


\section{Authors}

JIYEON JOY PARK, PharmD; LAUREN BOUTILLIER, PharmD, BCOP; GAEUN JOUNG, PharmD, BCPS; and JEFFREY NEMETH, PharmD, MPA, Englewood Hospital and Medical Center, Englewood, New Jersey. JOSEPH E. CRUZ, PharmD, BCPS, Englewood Hospital and Medical Center, Englewood, New Jersey, and Rutgers University Ernest Mario School of Pharmacy, Piscataway, New Jersey.

AUTHOR CORRESPONDENCE: Jiyeon Joy Park, PharmD, Rutgers University Ernest Mario School of Pharmacy, 160 Frelinghuysen Rd., Piscataway, NJ 08854. Tel.: 848.236.2298;

E-mail: jiyeonp@cinj.rutgers.edu.

\section{DISCLOSURES}

No outside funding supported this research. The authors have nothing to disclose.

This research was presented as a poster at the ASHP Midyear Clinical Meeting \& Exhibition 2017; December 3-7, 2017; Orlando, FL.

\section{REFERENCES}

1. Schumock GT, Li EC, Wiest MD, et al. National trends in prescription drug expenditures and projections for 2017. Am J Health Syst Pharm. 2017;74(21):339-59

2. Truven Health Analytics, IBM Watson Health. Micromedex RED BOOK. Active ingredient: infliximab. February 1, 2018. Database. Available at: http://truvenhealth.com/Products/Micromedex/Product-Suites/ClinicalKnowledge/RED-BOOK. Accessed July 31, 2018.

3. Truven Health Analytics, IBM Watson Health. Infliximab. IBM Micromedex. Database. October 27, 2017. Available at: http://www.micromedexsolutions.com/home/dispatch. Accessed July 31, 2018.

4. Vandyke TH, Athmann PW, Ballmer CM, Kintzel PE. Cost avoidance from dose rounding biologic and cytotoxic antineoplastics. J Oncol Pharm Pract. 2017;23(5):379-83.

5. Paget C. Appropriate dose rounding of cytokine modulators for paediatric rheumatology inpatients. Arch Dis Child. 2016;101:e2.

6. Adler J, Sandberg KC, Shpeen BH, et al. Variation in infliximab administration practices in the treatment of pediatric inflammatory bowel disease. J Pediatr Gastroenterol Nutr. 2013;57(1):35-38.

7. Tkcaz J, Lofland JH, Vanderpoel J, Ruetsch C. Infliximab dosing patterns in a sample of patients with Crohn's disease: results from a medical chart review. Am Health Drug Benefits. 2014;7(2):87-93. 


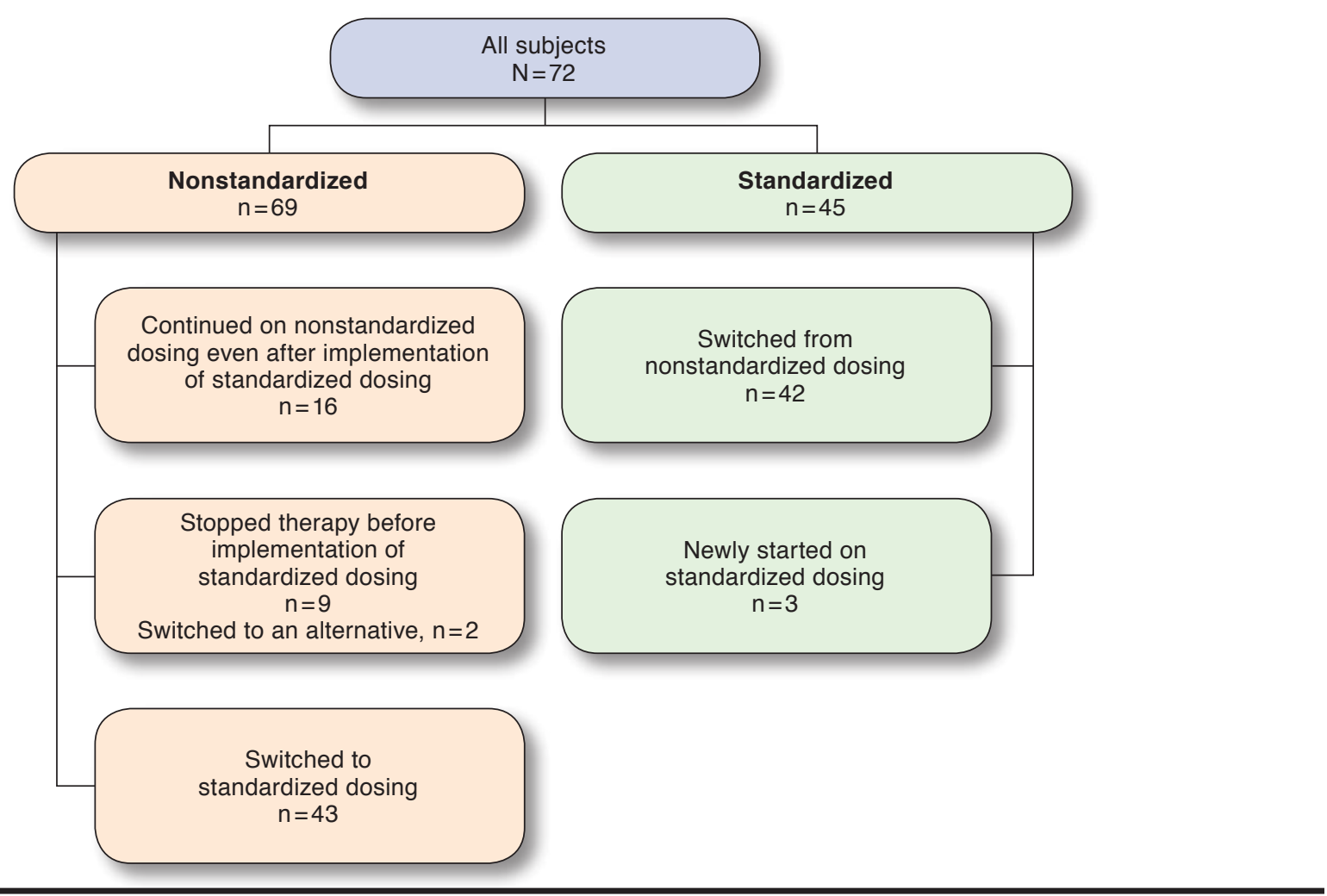

